\title{
Prevalence and risk factors for chronic bronchitis in Pelotas, RS, Brazil: a population- based study
}

\author{
Ana M B Menezes, Cesar G Victora, Mario Rigatto
}

\begin{abstract}
Background - Chronic bronchitis causes high morbidity and mortality throughout the world. It is basically a preventable disease. However, few population based studies of chronic bronchitis have been carried out in less developed countries.

Methods - A population based cross sectional survey was conducted to determine the prevalence of chronic bronchitis and associated risk factors in an urban area (Pelotas) of southern Brazil. 1053 subjects aged 40 years and over $(90 \cdot 3 \%$ of eligible subjects) were interviewed using the ATSDLD-78 questionnaire.

Results - Of the subjects interviewed $12 \cdot 7 \%$ were classified as having chronic bronchitis. In univariate analyses a significant increase in the relative odds of chronic bronchitis was seen in men $(O R=2 \cdot 17,95 \%$ CI 1.50 to $3 \cdot 13)$, low family income (OR= $2 \cdot 60,95 \%$ CI 1.47 to 4.47 for lowest quartile), low schooling (OR $=4 \cdot 65$, 95\% CI $2 \cdot 36$ to $9 \cdot 18$ for those with no schooling), smoking habits $(O R=6.92,95 \%$ CI 4.22 to $11 \cdot 36$ for smokers of 20 or more cigarettes per day), high occupational exposure to dust $(O R=2.48,95 \%$ CI 1.56 to 3.94$)$, inadequate housing $(\mathrm{OR}=2 \cdot 09,95 \% \mathrm{CI} 1 \cdot 22$ to $3 \cdot 58$ ), high level of indoor air pollution $(O R=1 \cdot 86,95 \%$ CI 1.16 to 2.99$)$, and reported childhood respiratory illnesses $(\mathrm{OR}=2 \cdot 08,95 \%$ CI $1 \cdot 25$ to $3 \cdot 49)$. Multiple logistic regression resulted in the identification of the following independent risk factors: family income $(O R=1 \cdot 99,95 \% \mathrm{CI}$ 1.04 to 3.81 for subjects in the lowest quartile compared with those in the highest quartile), schooling (OR $=5 \cdot 60,95 \%$ CI $2 \cdot 52$ to $12 \cdot 45$ for subjects with no schooling compared with those with nine or more years), smoking (OR $=8 \cdot 10,95 \%$ CI 4.46 to 14.71 for smokers of 20 or more cigarettes per day compared with non-smokers), and history of major respiratory illnesses in childhood $(O R=2 \cdot 16,95 \%$ CI $1 \cdot 20$ to 3.85$)$. Conclusions - Low family income, poor schooling, smoking, and childhood respiratory illnesses were significantly associated with chronic bronchitis.
\end{abstract}

(Thorax 1994:49:1217-1221)

Reprint requests to: Dr AMB Menezes.

Received 25 January 1994 Returned to authors 20 April 1994

Revised version received

27 June 1994

Accepted for publication

2 September 1994
Chronic bronchitis, despite being potentially preventable, causes high morbidity and mortality. ${ }^{1}$ Studies from different countries have shown high prevalence rates for chronic bron- chitis such as $17 \%$ in England, ${ }^{2} 15.6 \%$ in London, ${ }^{3}$ and $18.3 \%$ in Nepal. ${ }^{4}$ The primary risk factors for chronic bronchitis such as smoking have been well established in population studies from industrialised countries, ${ }^{5-9}$ and other potential risk factors such as occupational exposures, poor housing, indoor air pollution, and childhood respiratory illnesses have also been identified. ${ }^{10-15}$ However, the prevalence of chronic bronchitis in Brazil and other Latin American countries, and the relative importance of some of these risk factors, are not known.

Although the association between chest illness in childhood and later respiratory morbidity is now well documented in developed countries, ${ }^{16} 17$ some questions are still raised about the underlying mechanism of such an association. Infections of the lower respiratory tract are much more common in less developed countries, ${ }^{18}$ and it is important to ascertain whether this is linked with chronic bronchitis.

The present study was aimed at measuring the prevalance of chronic bronchitis in a population based sample in a southern Brazilian city, as well as investigating some risk factors for the disease by multivariate analyses. Since studies from less developed countries are uncommon, this would allow one to verify whether risk factors operating in industrialised countries have a similar role elsewhere.

\section{Methods}

The study covered a representative sample of the population aged 40 years and over living in the urban area of Pelotas, a city of 300000 inhabitants in southern Brazil, near the Uruguayan border. Although Pelotas is situated in a relatively well developed agricultural area, wide social inequalities persist. The survey was conducted from June to September (winter months) of 1990.

The urban area of Pelotas is made up of 250 census tracts, each including approximately 300 households; 40 of these were randomly selected for inclusion in the study. In each tract a starting point was randomly chosen on a map, and every fifth household moving in a counterclockwise direction was selected until 30 were reached. This sampling scheme gave every individual in the city population the same chance of being selected. Ten medical studens conducted the interviews in the homes of the subjects and the houses were revisited if no residents were home. After three attempts on different dates they were considered refusals; these were not replaced. Ten percent of the 
visits were repeated by a supervisor to ensure that the sampling procedures had been adequate, that the interviews had taken place, and to check the repeatability of the questions.

All subjects were interviewed using the questionnaire ATS-DLD-78 ${ }^{1}$ which was adapted to suit local conditions. The questionnaire also elicited demographic information and data on family income, schooling, occupational exposure to dust, smoking habits, passive smoking, quality of housing, indoor air pollution, and childhood respiratory illnesses.

The following definitions were used:

(1) Chronic bronchitis: cough and sputum production during the majority of days for at

Table 1 Prevalence of chronic bronchitis according to socioeconomic and demographic variables

\begin{tabular}{|c|c|c|c|}
\hline Variables & $\begin{array}{l}\text { No. of } \\
\text { subjects }\end{array}$ & $\begin{array}{l}\text { Prevalence of chronic } \\
\text { bronchitis (\%) }\end{array}$ & $\chi^{2}$ \\
\hline $\begin{array}{l}\text { Age (years) } \\
40-49 \\
50-59 \\
60-69 \\
\geqslant 70\end{array}$ & $\begin{array}{l}378 \\
338 \\
223 \\
114\end{array}$ & $\begin{array}{r}9 \cdot 8 \\
16 \cdot 0 \\
12 \cdot 1 \\
14 \cdot 0\end{array}$ & $>0.05$ \\
\hline $\begin{array}{l}\text { Gender } \\
\text { Female } \\
\text { Male }\end{array}$ & $\begin{array}{l}623 \\
430\end{array}$ & $\begin{array}{r}9 \cdot 1 \\
17.9\end{array}$ & $<0.001$ \\
\hline $\begin{array}{l}\text { Race } \\
\text { White } \\
\text { Others }\end{array}$ & $\begin{array}{l}868 \\
185\end{array}$ & $\begin{array}{l}12 \cdot 4 \\
14 \cdot 1\end{array}$ & $>0.05$ \\
\hline $\begin{array}{l}\text { Family income (quartile)* } \\
<25 \% \\
25-49 \% \\
50-74 \% \\
75-100 \%\end{array}$ & $\begin{array}{l}256 \\
253 \\
260 \\
256\end{array}$ & $\begin{array}{r}18 \cdot 0 \\
15 \cdot 4 \\
10 \cdot 4 \\
7 \cdot 8\end{array}$ & $<0.001$ \\
\hline $\begin{array}{l}\text { Schooling (years) } \\
\text { None } \\
1-4 \\
5-8 \\
\geqslant 9\end{array}$ & $\begin{array}{l}241 \\
355 \\
273 \\
180\end{array}$ & $\begin{array}{r}22.8 \\
11.8 \\
9.5 \\
6.1\end{array}$ & $<0.001$ \\
\hline
\end{tabular}

* This information was missing for 28 persons

** This information was missing for 4 persons.

Table 2 Prevalence of chronic bronchitis according to smoking and passive smoking

\begin{tabular}{|c|c|c|c|}
\hline Variables & $\begin{array}{l}\text { No. of } \\
\text { subjects }\end{array}$ & $\begin{array}{l}\text { Prevalence of chronic } \\
\text { bronchitis (\%) }\end{array}$ & $\chi^{2}$ \\
\hline $\begin{array}{l}\text { Smoking } \\
\text { Non-smoker } \\
\text { Ex-smoker } \\
1-19 \\
\geqslant 20\end{array}$ & $\begin{array}{l}464 \\
233 \\
185 \\
171\end{array}$ & $\begin{array}{r}6 \cdot 3 \\
11 \cdot 6 \\
13 \cdot 0 \\
31 \cdot 6\end{array}$ & $<0.001$ \\
\hline $\begin{array}{l}\text { Passive smoking (exposure) } \\
\text { None } \\
\text { Moderate } \\
\text { High }\end{array}$ & $\begin{array}{l}275 \\
469 \\
309\end{array}$ & $\begin{array}{l}11 \cdot 6 \\
11.9 \\
14 \cdot 9\end{array}$ & $>0.05$ \\
\hline $\begin{array}{l}\text { Occupational exposure to dust } \\
\text { None } \\
\text { Low } \\
\text { Middle } \\
\text { High }\end{array}$ & $\begin{array}{l}530 \\
136 \\
213 \\
174\end{array}$ & $\begin{array}{r}9 \cdot 8 \\
10 \cdot 3 \\
14 \cdot 6 \\
21 \cdot 3\end{array}$ & $<0.001$ \\
\hline $\begin{array}{l}\text { Housing } \\
\text { Adequate } \\
\text { Middle } \\
\text { Inadequate }\end{array}$ & $\begin{array}{l}511 \\
424 \\
118\end{array}$ & $\begin{array}{l}10 \cdot 4 \\
13 \cdot 7 \\
19 \cdot 5\end{array}$ & $<0.05$ \\
\hline $\begin{array}{l}\text { Indoor pollution (exposure) } \\
\text { None } \\
\text { Moderate } \\
\text { High }\end{array}$ & $\begin{array}{l}411 \\
385 \\
257\end{array}$ & $\begin{array}{r}9 \cdot 3 \\
14 \cdot 0 \\
16 \cdot 0\end{array}$ & $<0.05$ \\
\hline $\begin{array}{l}\text { Childhood respiratory illnesses } \\
\text { No } \\
\text { Yes }\end{array}$ & $\begin{array}{l}952 \\
101\end{array}$ & $\begin{array}{l}11 \cdot 8 \\
22 \cdot 8\end{array}$ & $<0.001$ \\
\hline
\end{tabular}

least three consecutive months in the previous two or more successive years. ${ }^{2}$

(2) Occupational exposure to dust: self-reported degree of occupational exposure to dust: none, low, middle or high.

(3) Smoking habits: including smoking status (never/ex/current smoker) and current number of cigarettes smoked daily.

(4) Passive smoking: data were collected on passive exposure to smoking at home, at work, and in leisure time, expressed as times per week; none, moderate (1-7 times/week) or high exposure (more than 7 times/week).

(5) Indoor pollution: investigated by asking the subjects about the type of cooking, lighting, and heating in the houses where they had lived most of their lives. A score was developed as follows: no source of smoke, moderate (one source of smoke: a range or open fire or charcoal stove or paraffin lamp or a coal heater) and high exposure (two or more of the above sources). (6) Quality of housing: reported information on the house the subject had lived in for most of his/her life. Houses were considered as adequate if materials such as bricks or cement were used, inadequate if irregular materials (such as mud, wooden boards, cardboard) were used, and intermediate if otherwise.

(7) Childhood respiratory illnesses: self-report of any important respiratory illness (respiratory disease leading to hospital admission or medical treatment before the age of 16 years).

\section{DATA ANALYSIS}

Analysis of the risk factors for chronic bronchitis was performed using the programme EGRET. ${ }^{19}$ Logistic regression was used for calculating odds ratios and significance tests (likelihood ratio test) and to adjust each variable for the effects of the remainder. ${ }^{20}$ The projected sample size of 1200 was sufficient for detecting a prevalence ratio of 2 with $90 \%$ power at the $5 \%$ significance level, if the prevalence in the unexposed subjects equalled $7 \%$ and the frequency of exposure ranged from $20 \%$ to $80 \%$.

\section{Results}

Of 1200 adults meeting the age criteria living in the sample households, 1053 (90.3\%) participated in the study. The prevalence of chronic bronchitis in this sample was $12.7 \%$ ( $95 \%$ confidence interval $10 \cdot 6 \%$ to $14 \cdot 7 \%$ ).

There was no overall significant association between chronic bronchitis and age, though prevalence was highest in the group aged 50-59 years. Men were 1.96 times more likely to have chronic bronchitis than women, but there was no association with race (table 1 ). Family income and schooling were inversely associated with chronic bronchitis, subjects with no formal schooling having a 3.73 times greater risk than those with none or more years of schooling, and subjects on the lowest quartile of family income were 2.3 times more likely to have chronic bronchitis than those in the highest quartile.

Cigarette smokers of 20 or more per day were five times more likely to have chronic 
Table 3 Multiple logistic regression analysis of risk factors for chronic bronchitis adjusted for confounding variables

\begin{tabular}{|c|c|c|}
\hline Variables & Crude & Adjusted for all other variables* \\
\hline $\begin{array}{l}\text { Gender } \\
\text { Female } \\
\text { Male } \\
\text { LRT }\end{array}$ & $\begin{array}{l}1.00 \\
2 \cdot 17(1.50 \text { to } 3 \cdot 13) \\
p<0.001\end{array}$ & $\begin{array}{l}1.00 \\
1.30(0.82 \text { to } 2.07) \\
p>0.05\end{array}$ \\
\hline $\begin{array}{l}\text { Age (years) } \\
40-49 \\
50-59 \\
60-69 \\
\geqslant 70 \\
\text { LRT }\end{array}$ & $\begin{array}{l}1.00 \\
1.75(1.12 \text { to } 2.74) \\
1.27(0.75 \text { to } 2.15) \\
1.51(0.80 \text { to } 2.82) \\
\text { p }>0.05\end{array}$ & $\begin{array}{l}1.00 \\
1.55(0.94 \text { to } 2.55) \\
1.32(0.73 \text { to } 2 \cdot 40) \\
1.84(0.88 \text { to } 3.80) \\
p>0.05\end{array}$ \\
\hline $\begin{array}{l}\text { Race } \\
\text { White } \\
\text { Others } \\
\text { LRT }\end{array}$ & $\begin{array}{l}0.87(0.55 \text { to } 1.38) \\
1.00 \\
p<0.001\end{array}$ & $\begin{array}{l}1.27(0.75 \text { to } 2.14) \\
1.00 \\
p>0.05\end{array}$ \\
\hline $\begin{array}{l}\text { Schooling (years) } \\
\text { No schooling } \\
1-4 \\
5-8 \\
\geqslant 9 \\
\text { LRT }\end{array}$ & $\begin{array}{l}4.65(2.36 \text { to } 9.18) \\
2.11(1.06 \text { to } 4.21) \\
1.65(0.80 \text { to } 3.44) \\
1.00 \\
p<0.001\end{array}$ & $\begin{array}{l}5.60(2.52 \text { to } 12 \cdot 45) \\
2 \cdot 45(1.14 \text { to } 5 \cdot 26) \\
1.85(0.84 \text { to } 4 \cdot 07) \\
1.00 \\
p<0.001\end{array}$ \\
\hline $\begin{array}{l}\text { Family income (quartile) } \\
<25 \% \\
25-49 \% \\
50-74 \% \\
75-100 \% \\
\text { LRT }\end{array}$ & $\begin{array}{l}2.60(1.47 \text { to } 4.47) \\
2.00(1.13 \text { to } 3.50) \\
1.40(0.76 \text { to } 2.56) \\
1.00 \\
\text { p }<0.001\end{array}$ & $\begin{array}{l}1.99(1.04 \text { to } 3.81) \\
1.80(0.96 \text { to } 3.40) \\
1.19(0.61 \text { to } 2.32) \\
1.00 \\
p<0.05\end{array}$ \\
\hline $\begin{array}{l}\text { Smoking (years) } \\
\text { Non-smoker } \\
\text { Ex-smoker } \\
1-19 \\
\geqslant 20 \\
\text { LRT }\end{array}$ & $\begin{array}{l}1.00 \\
1.97(1.14 \text { to } 3.40) \\
2 \cdot 24(1.26 \text { to } 3.96) \\
6.92(4.22 \text { to } 11.36) \\
\text { p }<0.001\end{array}$ & $\begin{array}{l}1.00 \\
1.59(0.85 \text { to } 2 \cdot 96) \\
2 \cdot 36(1.24 \text { to } 4.46) \\
8 \cdot 10(4.46 \text { to } 14 \cdot 71) \\
\text { p }<0.001\end{array}$ \\
\hline $\begin{array}{l}\text { Passive smoking } \\
\text { No exposure } \\
\text { Intermediate exposure } \\
\text { High exposure } \\
\text { LRT }\end{array}$ & $\begin{array}{l}1.00 \\
1.03(0.65 \text { to } 1.64) \\
1.33(0.82 \text { to } 2 \cdot 15) \\
p>0.05\end{array}$ & $\begin{array}{l}1.00 \\
0.86(0.52 \text { to } 1.44) \\
0.94(0.54 \text { to } 1.63) \\
p>0.05\end{array}$ \\
\hline $\begin{array}{l}\text { Degree of occupational ex } \\
\text { None } \\
\text { Few } \\
\text { Middle } \\
\text { High } \\
\text { LRT }\end{array}$ & $\begin{array}{l}\text { e to dust } \\
1.00 \\
1.06(0.57 \text { to } 1.97) \\
1.57(0.97 \text { to } 2.52) \\
2.48(1.56 \text { to } 3.94) \\
\text { p }<0.001\end{array}$ & $\begin{array}{l}1.00 \\
0.97(0.50 \text { to } 1.93) \\
1.38(0.81 \text { to } 2.33) \\
1.49(0.87 \text { to } 2.54) \\
\text { p }>0.05\end{array}$ \\
\hline $\begin{array}{l}\text { Housing } \\
\text { Adequate } \\
\text { Middle } \\
\text { Inadequate } \\
\text { LRT }\end{array}$ & $\begin{array}{l}1.00 \\
1.37(0.92 \text { to } 2.03) \\
2.09(1.22 \text { to } 3.58) \\
\mathrm{p}<0.05\end{array}$ & $\begin{array}{l}1.00 \\
1.06(0.67 \text { to } 1.69) \\
1.24(0.65 \text { to } 2.38) \\
p>0.05\end{array}$ \\
\hline $\begin{array}{l}\text { Indoor pollution } \\
\text { Minimum } \\
\text { Middle } \\
\text { High } \\
\text { LRT }\end{array}$ & $\begin{array}{l}1.00 \\
1.64(1.05 \text { to } 2.54) \\
1.86(1.16 \text { to } 2.99) \\
\mathrm{p}=0.01\end{array}$ & $\begin{array}{l}1.00 \\
1.49(0.92 \text { to } 2.41) \\
1.30(0.75 \text { to } 2.27) \\
p>0.05\end{array}$ \\
\hline $\begin{array}{l}\text { Childhood respiratory illn } \\
\text { No } \\
\text { Yes } \\
\text { LRT }\end{array}$ & $\begin{array}{l}1.00 \\
2.08(1.25 \text { to } 3.49) \\
p<0.01\end{array}$ & $\begin{array}{l}1 \cdot 00 \\
2 \cdot 16(1 \cdot 20 \text { to } 3 \cdot 85) \\
p=0 \cdot 01\end{array}$ \\
\hline
\end{tabular}

* Adjusted for age, gender, schooling, family income, smoking, passive smoking, exposure to dust, housing, indoor pollution, childhood respiratory infections.

LRT $=$ logistic regression trend

Values are odds ratios (95\% confidence intervals). adjusted for all other variables in the model including family income, schooling, smoking habits, passive smoking, occupational exposure to dust, housing, indoor pollution, and childhood respiratory illnesses. The excess risk associated with male gender was greatly reduced and became non-significant after adjustments were made. Age remainded non-significant but there was a reduction in the odds ratio for the group aged 50-59 years; after adjustment the highest risk was for individuals aged 70 or over. The inverse association between chronic bronchitis and both family income and schooling seen in the crude analysis remained even after adjustments were made for confounding variables.

Smoking showed a significant dose-response effect; in the crude analysis the odds ratios were 1.97 for ex-smokers, 2.24 for smokers of 1-19 cigarettes, and 6.92 for smokers of 20 or more cigarettes daily compared with nonsmokers. This strong effect persisted after adjustment, the latter odds ratio increasing to $8 \cdot 10$. However, no association was found with passive smoking either in the crude or adjusted analyses.

Strong associations were also found between chronic bronchitis and other variables related to smoking, including the lifetime consumption of cigarettes, the age of starting, the time since quitting, the total duration of the habit, and the type of cigarettes. These analyses are not presented here.

Although the crude association between chronic bronchitis and occupational exposure to dust was significant, it was reduced and became non-significant after controlling for the other variables. The same occurred with inadequate housing and indoor pollution. Subjects who reported childhood respiratory illnesses had twice the risk of chronic bronchitis than those without such history. This effect persisted after adjustments.

\section{Discussion}

The prevalence of chronic bronchitis in Pelotas is similar to that reported from other studies, ${ }^{2-4}$ most of which have used the same diagnostic criteria. In interpreting the results of the above analyses it is important to take into account the hierarchical relationships between the risk factors under study. Age and gender, for example, may influence all other risk factors and their overall effect is properly assessed in a model in which only these two variables are included. The above results showed a doubling of the risk associated with male gender, and a peak in prevalence among 50-59 year old subjects.

The effects of age and gender, however, are likely to be mediated through other factors such as education, cigarette smoking, and occupational exposures. The reduction in the odds ratio associated with male gender (from 2.17 in the crude analysis to 1.30 after adjustment for all other variables) strongly supports the hypothesis that most, if not all, of the gender effect is due to behavioural and occupational risks rather than genetic differ- 
ences. The highest risk in the crude analysis was among 50-59 year olds. After taking into account that these individuals were the heaviest smokers in the sample, as well as differences in other mediating factors, the association became more linear with the highest risk among the oldest. These findings are therefore similar to those of Yamaguchi et $a l^{6}$ who showed no association between chronic bronchitis and either gender or age after adjustment for mediating variables. On the other hand, Iversen et $a l^{8}$ found age over 50 years to be a risk factor for chronic bronchitis in a multivariate analysis of Danish farmers.

The fact that the family income and schooling effects remained significant in the multivariate analyses suggests that there are other pathways than the variables included in the present analysis that link socioeconomic level to bronchitis. Socioeconomic variables such as income and education obviously cannot cause disease directly but their effect has to be mediated through a biological mechanism. These may include smoking, occupational exposures, past illnesses and others. Strachan ${ }^{21}$ mentions that one of the most puzzling, yet consistent, features of chronic respiratory disease, at least in Britain, has been its association with social class with a predilection for the least privileged groups. Smoking and occupational exposures are probably only part of the explanation and it is plausible to suggest a link between exposure during lung growth (before or after birth) and symptomatic chronic respiratory disease. ${ }^{21}$ Barker et al $^{16}$ observed reduced levels of ventilatory function and increased mortality from chronic respiratory disease among men of low birthweight.

Socioeconomic status also affects general attitudes toward disease prevention and early care seeking, both of which are difficult to measure in studies such as the present one. The precise nature of the mechanisms linking low socioeconomic status to chronic bronchitis requires further epidemiological and anthropological research.

The risk of smoking for chronic bronchitis has been well documented ${ }^{6-9}$ and is further confirmed in the present study. The strong association observed in the crude analysis was even greater after adjustment, implying the presence of negative confounding factors - that is, other variables leading to an underestimation of the effect of smoking. It has also been shown that, among smokers, those consuming handrolled cigarettes made with maize leaves had the highest risk. ${ }^{22}$ The remaining risk factors might have been confounded by all variables under study. Their effect, therefore, is best assessed in the multivariate analyses in table 3.

Subjects exposed to dust have been reported to show higher prevalences of chronic bronchitis than the unexposed, ${ }^{23}$ but this was not significant after controlling for other confounding variables in the present study.

Housing quality and indoor pollution were also associated with chronic bronchitis in the crude analysis, but not after controlling for confounding factors. Strachan and Sanders ${ }^{11}$ did not find any association between respiratory symptoms and household temperatures or humidity levels. Although $\mathrm{McCarthy} e t a l^{10}$ described an association between chronic bronchitis and inadequate housing, the latter classification was based on whether the house appeared to be "easy to rent", a definition which may have been inappropriate. Behera and Jindal ${ }^{24}$ studied the effect of domestic cooking fuels on respiratory symptoms in 3701 women and found that smoking women who were also exposed to cooking fuels experienced respiratory symptoms more often than nonsmokers. Pandey ${ }^{15}$ has also shown such an association between chronic bronchitis and average time per day spent near the fireplace. In Brazilian houses there are different sources of indoor smoke (range, open fire, charcoal stove, paraffin lamp, coal heater); the assessment of indoor pollution was therefore based on the number of sources of smoke.

There is evidence in the literature that respiratory infections during childhood may be responsible for adult respiratory disease..$^{25-28}$ The severity of childhood respiratory diseases can certainly be reduced by early and appropriate case management. ${ }^{27}$ The incidence of infection of the lower respiratory tract can also be prevented by a number of interventions including vaccination against measles, pertussis, and the new pneumococcal vaccines. ${ }^{27}$ Avoidance of exposure to smoke (environmental tobacco smoke, indoor biomass pollution) may also reduce infections of the lower respiratory tract and nutritional interventions may also assist by improving birthweight, promoting breast feeding, and reducing malnutrition. ${ }^{27}$

Cross sectional studies such as the present one may be affected by a number of different types of bias. The use of a representative, population based sample through home visits, and the relatively high participation rate $(>90 \%)$, suggest that selection bias was unlikely. Interviewers were unaware of the study objectives and $10 \%$ of the interviews were repeated by a supervisor and showed excellent agreement. Interview bias, therefore, is also unlikely. Measurement errors in the outcome variable were minimised by using an internationally standardised questionnaire which had been previously validated in Brasil. ${ }^{29}$ Some of the exposure variables may, however, have been affected by bias - that is, differential recall between cases and non-cases. The finding of an association between childhood respiratory infections and chronic adult respiratory disease may be attributable to bias since subjects with chronic bronchitis may have better recall of childhood respiratory events.

In conclusion, the present study showed that four potentially preventable risk factors - low family income, poor schooling, smoking, and childhood respiratory illnesses - were significantly associated with chronic bronchitis after adjustment for possible confounders. Such information may be useful for promoting socioeconomic changes, as well as for designing specific preventive campaigns against smoking and for improved treatment of childhood respiratory problems. 
1 Report from the Department of Clinical Epidemiology, National Heart and Lung Institute, London. Respiratory disease in England and Wales. Thorax 1988;43:949-54.

2 Richards IDG, Baker MR. Diseases of the respiratory system. The epidemiology and prevention of important diseases. Edinburgh: Churchill Livingstone, 1988;67-77.

3 Reid DD, Hamilton PJS, Keen H, Brett GZ, Jarrett RJ, Rose G. Cardiorespiratory disease and diabetes among middle-aged male civil servants. Lancet 1974;469-73.

4 Pandey MR. Prevalence of chronic bronchitis in a rural community of the Hill region of Nepal. Thorax 1984;39: 331-6.

5 La Vecchia C, Pagano R, Negri E, Decarli A. Smoking and prevalence of disease in the 1983 Italian National Health Survey. Int $\mathcal{F}$ Epidemiol 1988;17:50-5.

6 Yamaguchi S, Kano K, Shimojo N, Sano K, Xu X, Hirokatsuwatanabe $\mathrm{L}$, et al. Risk factors in chronic obstructive pulmonary malfunction and "chronic bronchitis" symptons in Beijing district: a joint study between Japan and China. F Epidemiol Community Health 1988;43:1-6

7 Burr ML, Holliday R. Why is chest disease so common in South Wales? Smoking, social class, and lung function: a survey of elderly men in two areas. $\mathcal{F}$ Epidemiol Community Health 1987;41:140-4.

8 Iversen M, Dahl R, Korsgaard J, Hallas T, Jensen EJ. Respiratory symptoms in Danish farmers: an epidemiological study of risk factors. Thorax 1988;43:872-7.

9 Tehro OE, Husman K, Vohlonen I, Heinonen OP. Atopy, smoking and chronic bronchitis. $\mathcal{F}$ Epidemiol Community Health 1987;41:300-95.

10 McCarthy P, Byrne D, Harrison S, Keighley J. Respiratory conditions: effect of housing and other factors $\mathcal{F}$ Epidemiol Community Health 1985;39:15-9.

11 Strachan DP, Sanders CH. Damp housing and childhood asthma; respiratory effects of indoor air temperature and
relative humidity. $¥$ Epidemiol Community Health 1989;43: relative

12 Melia RJW, Chinn S, Rona RJ. Respiratory illness and home environment of ethnic groups. $B M \mathcal{F} 1988 ; 296$ : 1438-41.

13 Cooreman J, Redon S, Levallois M, Liard R, Perdrizet S Respiratory history during infancy and childhood and respiratory conditions in adulthood. Int $\mathcal{F}$ Epidemiol 1990; 19:621-7

14 Bakke PS, Baste V, Hanoa R, Gulsvik A. Prevalence of obstructive lung disease in a general population: relation to occupational title and exposure to some airborne agents. Thorax 1991;46:863-70.

15 Pandey MR. Domestic smoke pollution and chronic bron- chitis in a rural community of the Hill region of Nepal. Thorax 1984;39:337-9.

16 Barker DJP, Godfrey KM, Fall C, Osmond C, Winter PD, Shaheen SO. Relation of birth weight and childhood respiratory infection to adult lung function and death from chronic obstructive lung disease. BMF 1991;303:671-5.

17 Samet JM, Tager IB, Speizer FE. The relationship between respiratory illness in childhood and chronic air-flow obstruction in adulthood. Am Rev Respir Dis 1983;127: 508-23.

18 Graham NMH. The epidemiology of acute respiratory infections in children and adults: a global perspective. $E_{p}$ idemiol Rev 1990;12:149-78.

19 EGRET. Epidemiological graphs, estimation and testing package. Washington: Statistics and Epidemiology Research Corporation, 1988.

20 Breslow NE, Day NE. Statistical methods in cancer research. Vol. I. The analysis of case-control studies. IARC Scientific Publications No. 32. Lyon: International Agency for Research on Cancer, 1980

21 Strachan DP. Causes and control of chronic respiratory disease: looking beyond the smokescreen. $f$ Epidemiol Community Health 1992;46:177-9.

22 Menezes AMB, Victora CG, Rigatto M. Chronic bronchitis and the type of cigarette smoked. Int 7 Epidemiol 1994 (in press)

23 Higgins ITT. The epidemiology of chronic respiratory disease. Prev Med 1973;2:14-33.

24 Behera D, Jindal SK. Respiratory symptoms in Indian women using domestic cooking fuels. Chest 1991;100:385-8.

25 Colley JRT, Douglas JWB, Reid DD. Respiratory disease in young adults: influence of early childhood respiratory tract illness, social class, air pollution and smoking. $B M \mathcal{F}$ 1973;3:195-8.

26 Kiernan KE, Colley JRT, Douglas JWB, Reid DD. Chronic cough in young adults in relation to smoking habits, childhood environment and chest illness. Respiration 1976 33:236-44.

27 Holland WW, Bailey P, Bland JM. Long term consequences of respiratory disease in infancy. $\mathcal{F}$ Epidemiol Community Health 1978;32:256-61.

28 Selwyn BJ. The epidemiology of acute respiratory tract infection in young children: comparison of findings from several developing countries. Rev Infect Dis 1990;12:S870-88.

29 Aguiar VAN, Beppu OS, Romaldini H, Rato OR, Nakatami J. Validacao de um questionario modificado (ATS-DLD78) como instrumento de um estudo epidemiologico em nosso meio. F Pneumol 1988;14:111-16. 